\title{
Collisions damage assessment of ships and jack-up rigs
}

\author{
Zhang, Shengming; Pedersen, P. Terndrup; Ocakli, Hasan
}

Published in:

Ships and Offshore Structures

Link to article, DOI:

$10.1080 / 17445302.2014 .1003173$

Publication date:

2015

Document Version

Peer reviewed version

Link back to DTU Orbit

Citation (APA):

Zhang, S., Pedersen, P. T., \& Ocakli, H. (2015). Collisions damage assessment of ships and jack-up rigs. Ships and Offshore Structures, 10(5), 470-478. https://doi.org/10.1080/17445302.2014.1003173

\section{General rights}

Copyright and moral rights for the publications made accessible in the public portal are retained by the authors and/or other copyright owners and it is a condition of accessing publications that users recognise and abide by the legal requirements associated with these rights.

- Users may download and print one copy of any publication from the public portal for the purpose of private study or research.

- You may not further distribute the material or use it for any profit-making activity or commercial gain

- You may freely distribute the URL identifying the publication in the public portal

If you believe that this document breaches copyright please contact us providing details, and we will remove access to the work immediately and investigate your claim 


\title{
COLLISIONS DAMAGE ASSESSMENT OF SHIPS AND JACK-UP RIGS
}

\author{
Shengming Zhang \\ Lloyd's Register EMEA., Global Technology Centre, Southampton, UK \\ P Terndrup Pedersen \\ Department of Mechanical Engineering \\ Technical University of Denmark \\ Hasan Ocakli \\ Lloyd's Register Asia \\ Republic of Korea
}

\section{ABSTRACT}

Ship collision with offshore installations is one of the key concerns in design and assess of platforms performance and safety. This paper presents an analysis on collision energy and structural damage in ship and offshore platform collisions for various collision scenarios. The platform or rig is treated as either rigid or flexible and its sensitivity on collision energy and structural damage is studied. An application example where an ice-strengthened supply vessel collides against a Jack-up rig is analyzed and the crushing resistance of the involved thin-walled structures is evaluated.

\section{INTRODUCTION}

Offshore platforms and drilling rigs are constantly serviced by supply vessels during its operations. Collisions between them are unavoidable. The key concern during design and operating of the structural system is to make sure that they have sufficient safety in case of collision incidents.

The current design practice is described for example in the Guidance Notes for Collision Analysis (2014) published by Lloyd's Register. Here a procedure is described and a number of recognized standards and practices for collision analysis are listed.

The basic impact design philosophy is that the offshore structure should be able to withstand accidental conditions from supply ships drifting out of control with a speed of $2 \mathrm{~m} / \mathrm{s}$. Such an impact may require major repair after the incident but not lead to total collapse even in a storm with a return period of one year. The size of traditional typical supply vessels is about 5,000 tonnes in displacement in the North Sea (Gjerde et al 1999). The size of supply vessels has increased in recent years. Vessels servicing the installations on the Norwegian Shelf have increased significantly up to 7500-10000 ton displacements (Storheim and Amdahl, 2014). With the increase in vessel size the collision energy will also increase. Thus the risk of damages in case of collisions with supply vessels could be significant. Therefore, such risks should be carefully assessed and reviewed (Pedersen 2014).

The aim of the present study is to present an analysis on collision energy and structural damage in ship and offshore jack-up rig collisions. An accurate assessment of damages to the offshore rig is complicated by the problem of specifying the relevant collision conditions such as ship structural arrangement, impact velocity, impact angle and position. It will be shown that it is important to take into account the jack-up flexibility in order to estimate the impact energy more accurately which is to be absorbed for structural damage. Application examples of vessels colliding to a jack-up rig are analysed and the crushing resistance of the thin-walled structures is evaluated.

\section{ANALYSIS METHODS FOR COLLISION ENERGY}

The analysis methods for collision energy between ships and offshore platforms were developed by the authors in references (Zhang 1999 and Pedersen \& Zhang 1998). The assumptions behind this calculation method are the platform natural period (typically about $8 \mathrm{~s}$ ) which is larger than the duration of the initial force contact between the colliding vessel and the platform, and that the global displacement of the topside of the jack-up is small until after the initial maximum contact forces between the colliding bodies is achieved. The procedure is also based on an assumption of ship translations in the horizontal plane only. The crushing load-deflection behavior is approximately linear, and that the structural response of the platform has a linear structural response.

The colliding system can be approximated as a two-mass system where one generalized mass represents the supply vessel and the other represents the platform, as shown in Figure 1. Thus, the following force-stiffness relations may represent the platform behavior:

$$
\begin{aligned}
& F_{\xi}=k_{11} \xi_{b}+k_{12} \xi_{p} \\
& F_{p}=k_{21} \xi_{b}+k_{22} \xi_{p}=-M_{p} \ddot{\xi}_{p}
\end{aligned}
$$

where $F_{\xi}$ is the collision force between the supply vessel and the platform, $F_{p}$ is the transmitted force acting on the generalized topside mass $M_{p}$ of the jack-up, $\xi_{b}$ is the 
displacement of the collision point on a leg, and $\xi_{p}$ is the displacement of the topside.
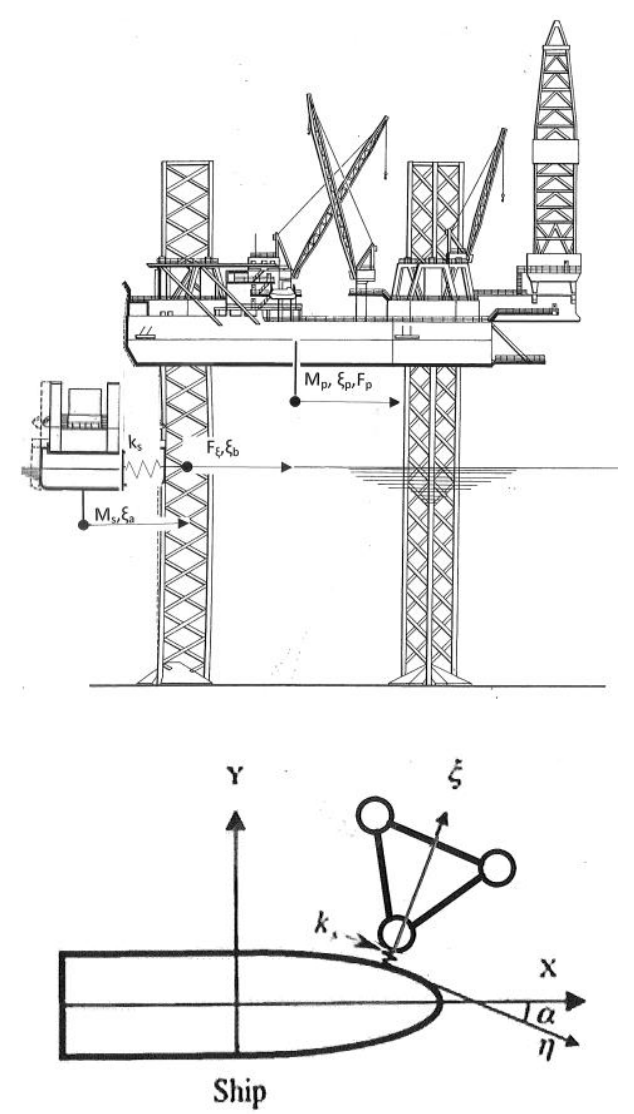

Figure 1. Simplified 2D model of a supply vessel impacting a chord of a jack-up platform

The interaction between the ship and the jack-up is simplified as:

$F_{\xi}=\left\{\begin{array}{lll}k_{s}\left(\xi_{a}-\xi_{b}\right), & \text { for } \dot{\xi}_{a}-\dot{\xi}_{b} \geq 0 \\ 0, & \text { for } \dot{\xi}_{a}-\dot{\xi}_{b}<0\end{array}\right.$

Here $k_{11}, k_{22}, k_{12}, k_{21}, k_{s}$ are stiffness coefficients, and $\xi_{a}$ is the displacement at the collision point of the supply vessel.

In Pedersen and Jensen (1991), it is shown that at the end of the collision where the velocities $\dot{\xi}_{a}=\dot{\xi}_{b}$, the displacement ( $\xi \mathrm{p}$ ) of the platform topside can be assumed to be small. Therefore, we get the generalized force at this moment:

$F_{p}=\frac{k_{21}}{k_{11}} F_{\xi}$
The impact impulse of the collision between the supply vessel and the platform can be expressed as:

$I_{\xi}=\frac{M_{a}}{D_{a \xi}}\left[\dot{\xi}(0)-\dot{\xi}_{a}\right]$

where,

$D_{a \xi}=\frac{1}{1+m_{a x}} \sin ^{2} \alpha+\frac{1}{1+m_{a y}} \cos ^{2} \alpha+$

$\frac{1}{1+j_{a}} \cdot \frac{\left[y_{c} \sin \alpha-\left(x_{c}-x_{a}\right) \cos \alpha\right]^{2}}{R_{a}^{2}}$

and $M_{a}$ is the mass of the supply vessel. The radius of the ship mass inertia around the centre of gravity is $R_{a}$, the coordinate of the centre of gravity of the striking ship is $\left(\mathrm{x}_{\mathrm{a}}, 0\right)$, the coordinate of the impact point is $\left(\mathrm{x}_{\mathrm{c}}, \mathrm{y}_{\mathrm{c}}\right)$, the added mass coefficient for the surge motion is $m_{a x}$ and it is taken 0.05 , the added mass coefficient for the sway motion is $m_{a y}$ and it is taken as 0.5 and the added mass coefficient of moment for the rotation around the centre of the gravity is $j_{a}$ and it is taken as 0.25 in this paper.

The impact impulse on the generalized platform mass can be expressed as:

$I_{p}=-M_{p} \dot{\xi}_{p}=\frac{k_{21}}{k_{11}} I_{\xi}$

At the end of the crushing, the velocity of the supply vessel and the velocity of the platform at the collision point are equal. We get:

$\dot{\xi}_{a}=-\frac{k_{12}}{k_{11}} \dot{\xi}_{p}$

The velocity of the topside of the platform is obtained as

$\dot{\xi}_{p}=-\frac{\dot{\xi}(0)}{\frac{k_{12}}{k_{11}}+\frac{k_{11}}{k_{21}} \frac{M_{p} D_{a \xi}}{M_{a}}}$

The velocity of the ship at the end of the collision can be expressed as: 
$v_{a x}=\dot{\xi}(0) \sin \alpha-\frac{\sin \alpha}{D_{a \xi}\left(1+m_{a x}\right)}\left(\dot{\xi}(0)-\dot{\xi}_{a}\right)$

$v_{a x}=\dot{\xi}(0) \cos \alpha-\frac{\cos \alpha}{D_{a \xi}\left(1+m_{a y}\right)}\left(\dot{\xi}(0)-\dot{\xi}_{a}\right)$

$\omega_{a}=\frac{y_{c} \sin \alpha-\left(x_{c}-x_{a}\right) \cos \alpha}{R_{a}^{2}\left(1+j_{a}\right) D_{a \xi}}\left(\dot{\xi}(0)-\dot{\xi}_{a}\right)$

where,

$$
\dot{\xi}(0)-\dot{\xi}_{a}=\frac{\dot{\xi}(0)}{1+\frac{k_{12} k_{21}}{k_{11}{ }^{2}} \frac{M_{a}}{M_{p} D_{a \xi}}}
$$

The energy to be absorbed by the crushing of the supply vessel and deformation of the jack-up rig is:

$$
E_{c}=E_{0}-\left(E_{s}+E_{p}\right)
$$

where,

$E_{0}=\frac{1}{2} M_{a}\left[\left(1+m_{a x}\right) \sin ^{2} \alpha+\left(1+m_{a y}\right) \cos ^{2} \alpha\right] \dot{\xi}(0)^{2}$ is the initial kinetic energy of the supply vessel,

$E_{p}=\frac{1}{2} \frac{M_{p} \dot{\xi}(0)^{2}}{\left(\frac{k_{12}}{k_{11}}+\frac{k_{11}}{k_{21}} \frac{M_{p} D_{a \xi}}{M_{a}}\right)^{2}}$ is the kinetic energy of the jack-up topside at the end of the collision,

$$
\begin{aligned}
& E_{s}=E_{0}+\frac{1}{2} M_{a} \dot{\xi}(0)^{2}\left(\frac{1}{D_{a \xi}\left(1+\frac{k_{12} k_{21}}{k_{11}{ }^{2}} \frac{M_{a}}{M_{p} D_{a \xi}}\right)^{2}}-\right. \\
& \left.\frac{2}{D_{a \xi}\left(1+\frac{k_{12} k_{21}}{k_{11}{ }^{2}} \frac{M_{a}}{M_{p} D_{a \xi}}\right)}\right)
\end{aligned}
$$

is the kinetic energy of the supply vessel at the end of the collision.

The energy to be dissipated by the crushing of the ship structure and/or the jack-up rig is:

$$
E_{\text {crush }}=\frac{k_{11}}{k_{11}+k_{s}}\left(E_{0}-E_{s}-E_{p}\right)
$$

The energy stored in the deformation of the platform is:

$$
E_{\text {platform }}=\frac{k_{s}}{k_{11}+k_{s}}\left(E_{0}-E_{s}-E_{p}\right)
$$

\section{DAMAGE ANALYSIS AND EXAMPLES}

\subsection{COLLISION ENERGY ANALYSIS OF SUPPLY VESSELS COLLIDING TO A JACK-UP RIG}

Let us consider an ice-strengthened supply vessel colliding with the leg of the jack-up rig in different locations of the ship at a velocity of $\mathrm{V}=2 \mathrm{~m} / \mathrm{s}$ in a direction normal to the colliding ship side. The length of the supply vessel is $82.5 \mathrm{~m}$, the breadth is $18.8 \mathrm{~m}$ and the displacement is $5,000 \mathrm{t}$. The jack-up rig is a self-elevating drilling rig with a topside overall length of $84 \mathrm{~m}$, width overall $90 \mathrm{~m}$ and depth $9.4 \mathrm{~m}$ capable of operation in water depth up to $100 \mathrm{~m}$. The generalized mass of the jack-up is 19700t which was determined from a calculation of the lowest natural frequency of the jack-up using a beam model where the fixity at the spud cans are estimated and the flexibility at the clamping mechanism is determined from a FEA. The legs of the rig were modelled as equivalent Timoshenko beams. The collision situation is illustrated in Figure 2. Other collision scenarios can be found in NORSOK 2004.

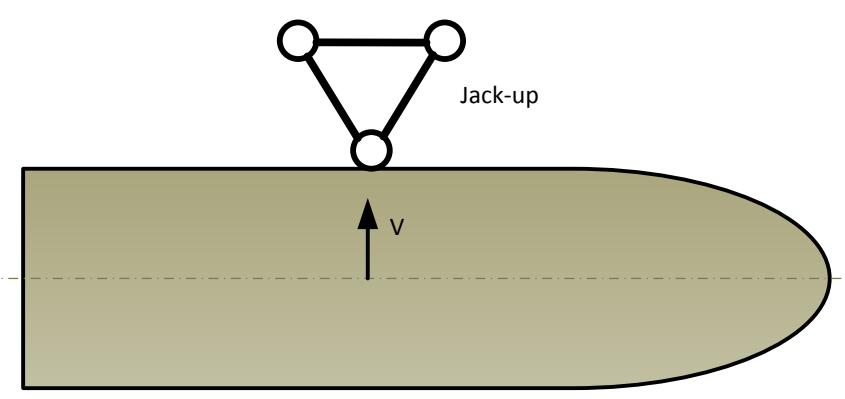

Figure 2. A supply vessel impacting a jack-up rig

Two collision cases were considered to show the effect of the structural flexibility on the impact energy; the jack-up rig was considered as rigid as well as flexible. For the flexible case, the stiffness coefficients in Table 1 are determined from the same beam model used for estimation of the generalized mass for the platform. The crushing stiffness $\mathrm{k}_{\mathrm{s}}$ refers to the results in Figure 7. For different impact locations Figure 3 shows the total kinetic energy of the supply vessel just before impact, the energy released for crushing of ship and/or platform in the case of a rigid platform and in the case of a flexible jack-up structure, and finally the elastic energy stored in global deformations of the jack-up.

Table 1: Stiffness coefficients for the flexible case

\begin{tabular}{|c|c|}
\hline Coefficients & MN/m \\
\hline$k_{11}$ & 34.5 \\
\hline$k_{22}$ & 48.9 \\
\hline$k_{12}=k_{21}$ & -27.8 \\
\hline$k_{s}$ & 48.0 \\
\hline
\end{tabular}


It is seen from the results in Figure 3 that the energies released for crushing are reduced considerably if the flexibility of the jack-up rig is considered. For the case where the supply vessel is colliding sideways to the rig with impact midship, the collision energy to be absorbed by structural crushing is $15 \mathrm{MJ}$ for the rigid case which is equal to the total initial kinetic energy and it is $5.03 \mathrm{MJ}$ for the flexible case. The platform absorbs $7 \mathrm{MJ}$ in elastic bending of the collided leg. The remaining energy of $2.97 \mathrm{MJ}$ is stored in the supply vessel and the platform in kinetic form. So, it is important to consider the flexibility of the platform in ship-platform collision analysis.

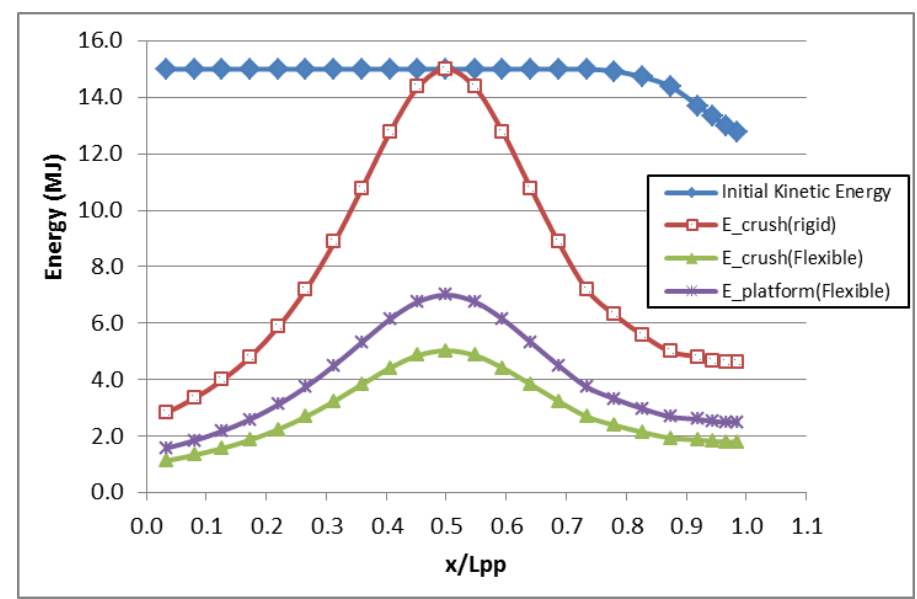

Figure 3. Energy analysis for the 5,000t supply vessel impacts the jack-up rig

If the jack-up rig hit by a $10,000 t$ vessel, the energies to be absorbed by crushing of the vessel and the platform are calculated and presented in Figure 4. It is seen that for the case where the supply vessel hits the rig sideway at midship, the ship and jack-up will absorb 8.39MJ by crushing and the jack-up leg will store $11.68 \mathrm{MJ}$ by elastic bending. The remaining energy of $9.93 \mathrm{MJ}$ is stored in the supply vessel and the platform in kinetic form.

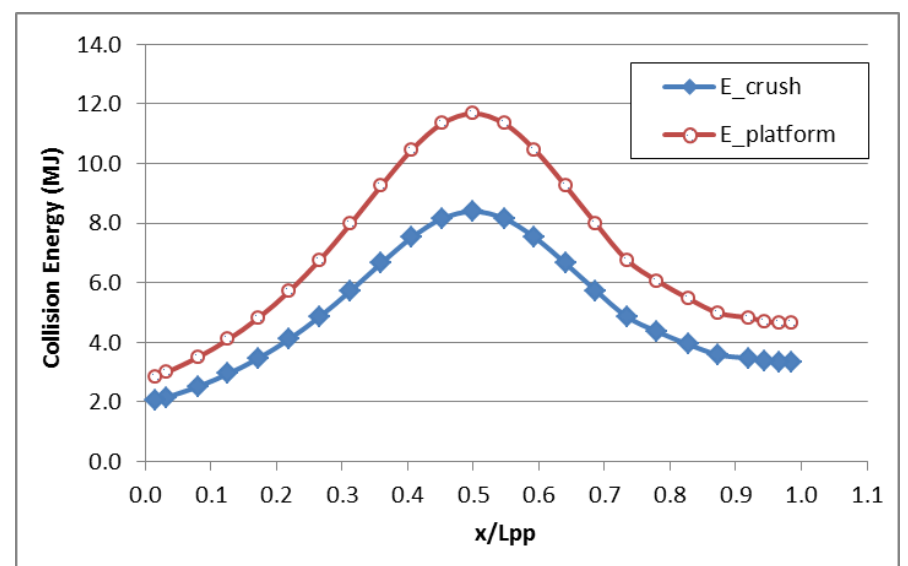

Figure 4. Collision energy to be absorbed by the 10,000t supply vessel and the platform
For a central head on collision the energy released for crushing of the bow and jack-up structure is found to be $5.88 \mathrm{MJ}$ for the $5000 \mathrm{t}$ supply vessel and $10.25 \mathrm{MJ}$ for $10000 \mathrm{t}$ vessel in the flexible case.

\subsection{DAMAGE ANALYSIS METHODOLOGY OF SUPPLY VESSELS COLLIDING TO A JACK-UP RIG}

When the colliding ship types and sizes and the distribution of energy released for crushing are known, the next step in a consequence analysis is to determine the distribution of crushing damages to be absorbed by the ships and to the jack-up structure.

The breakdown of damages between the involved structures depends on the relative strength of the ship structure and the impacted parts of the jack-up leg. If the ship is assumed to be infinitely stiff all the energy has to be dissipated by the jack-up structure. However, normally it will be much more cost effective to take into account the finite strength of the colliding ships. In this case both the striking ship and the installation will undergo local damage and absorb energy. When this is the situation the design is based on shared energy. If the strength of the jack-up is so large that the major part of the energy can be expected to be absorbed by the striking vessel then the installation is said to be strength designed. Thus, in order to determine the consequences of the energy released for structural damage, it is necessary first to determine the relative strength of the involved structures.

\subsection{LOCAL DAMAGE TO SUPPLY VESSEL}

The damage caused by the supply vessel can be estimated by detailed FEA, See for example Paik I and II 2007, and Samuelides 2014. But often also simplified procedures are used. The methodologies used in the following to determine the local capacity/damage of vessels were developed by the authors in references (Zhang 1999 and Pedersen \& Zhang 2000). Figure 5 illustrates the deformation/damage modes of a cylinder crushing into the side of a supply vessel. The main deformation mode in the side shell is plastic tension and it is folding and crushing in deck and bottom. Approximations for the forcedisplacement relations for side shell can be expressed as:

$$
\begin{aligned}
& F_{p}=\frac{4}{\sqrt{3}} \sigma_{0} t \delta\left(\frac{H}{b}\right)\left(\frac{b_{1}}{b}\right) \\
& b_{1}=b-b_{0} \\
& b_{0}=\frac{R}{b} \delta,\left(b_{0} \leq R\right)
\end{aligned}
$$

Approximations for the force-displacement relations for the deck or for the outer or inner bottom can be expressed as: 


$$
F_{d}=1.262 \sigma_{0} t^{1.83} b^{0.67} \frac{1}{\delta^{0.5}}+1.290 \sigma_{0} t^{1.33} \delta \frac{1}{b^{0.33}}
$$

where $\sigma_{0}$ is the flow stress of the materials (taking the average of the yield stress and tensile strength), $\mathrm{t}$ is the thickness, $\delta$ is the displacement (or penetration), $\mathrm{H}$ is the contact height of side shell, $\mathrm{b}$ is half of the frame spacing and $\mathrm{R}$ is the radius of the cylinder.

For ship bow crushing in head on collisions, simplified procedures such as illustrated in Yamada and Pedersen (2008) can be applied to determine the force penetration relations for ship bows.

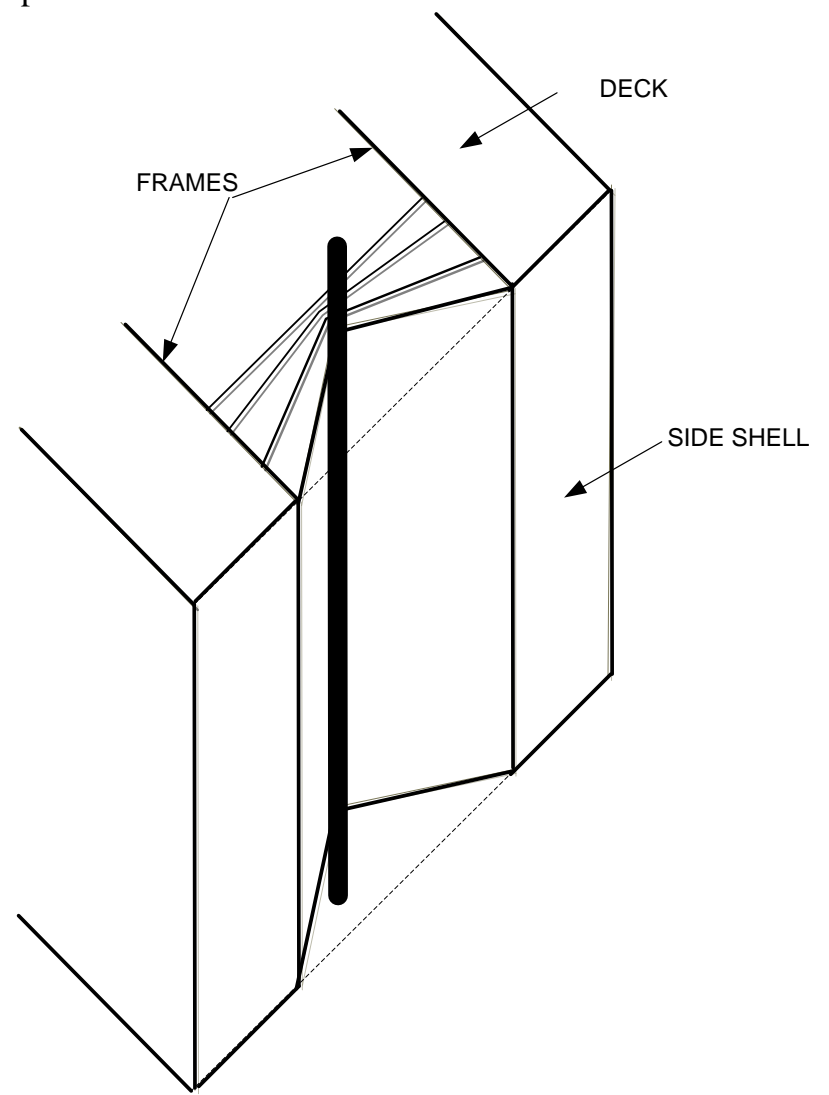

Figure 5. Illustration of the leg of a jack-up crushing into the midship of a supply vessel

Now we analyze the damage caused to a supply vessel colliding to a Jack-up rig. During design and operation of offshore platforms, one of the concerns is if the vessel is still intact and floating in case a collision occurs. Sinking of the vessel could cause massive damages, such as damages to the cables, pipelines under/around the platform and loss of lives.

Figure 6 illustrates a side collision scenario between a 5,000t an ice-strengthened supply vessel and a jack-up leg (the drawings are not scaled, detailed scantlings were omitted due to confidentiality). The diameter of the leg is assumed as $1 \mathrm{~m}$, and the cylinder leg is assumed rigid that it crushes into the ship side. The force-penetration curve and absorbed energypenetration curves are calculated and presented in Figure 7 and 8 , respectively.

The critical penetration point for the ship side is defined as the rupture of the side shell. At this point the absorbed energy by the ship is obtained as $20.8 \mathrm{MJ}$ and the maximum crushing force is $44.9 \mathrm{MN}$. The crushing forces for given penetrations are considerably higher than those in the NORSOK 2004.This may be due to the present example ship is an ice-strengthened and longitudinally stiffened ship.

This absorbed energy (20.8MJ) by ship structures is larger than the collision energy of $15 \mathrm{MJ}$ for the sideway collision of the supply vessel impact with the jack-up leg (rigid case). This means that the ship has sufficient energy absorption capability before rupturing of the side shell. So, in this example, the supply vessel is still intact and floating.

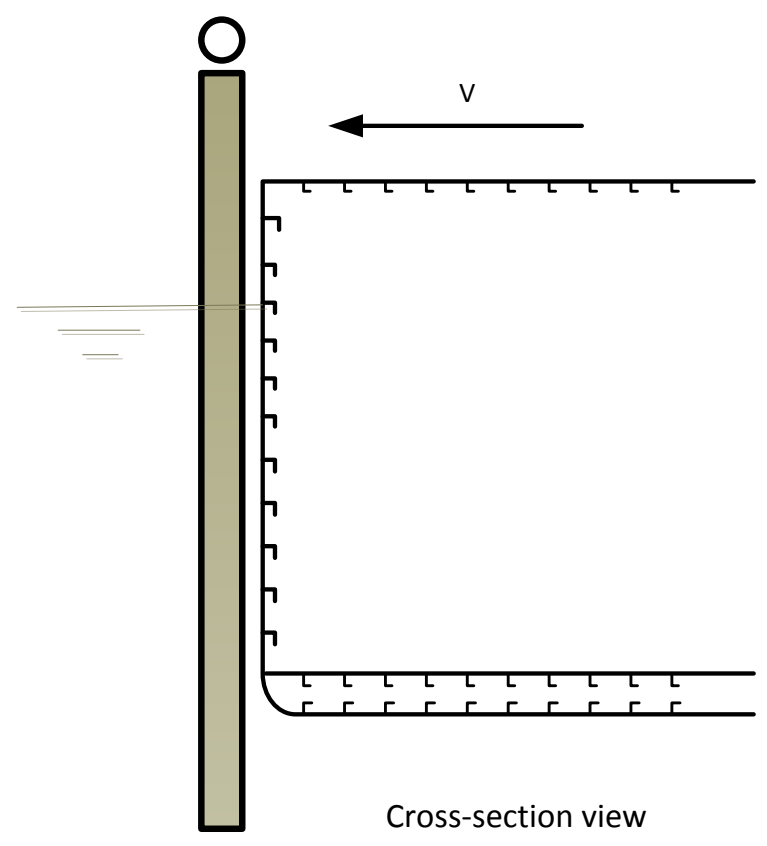

Figure 6. Collision between the jack-up rig and the supply vessel 


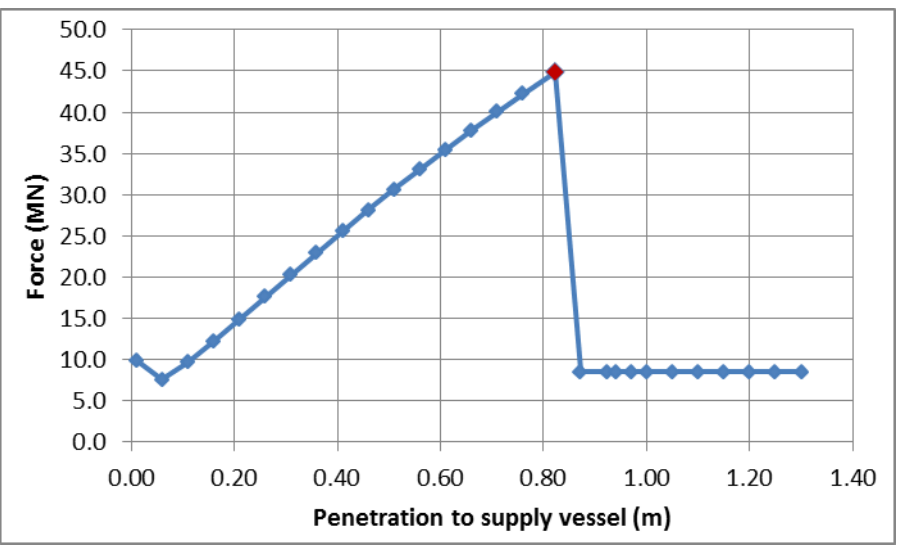

Figure 7. Force-penetration curve of the supply vessel crushing onto the jack-up leg (rigid case)

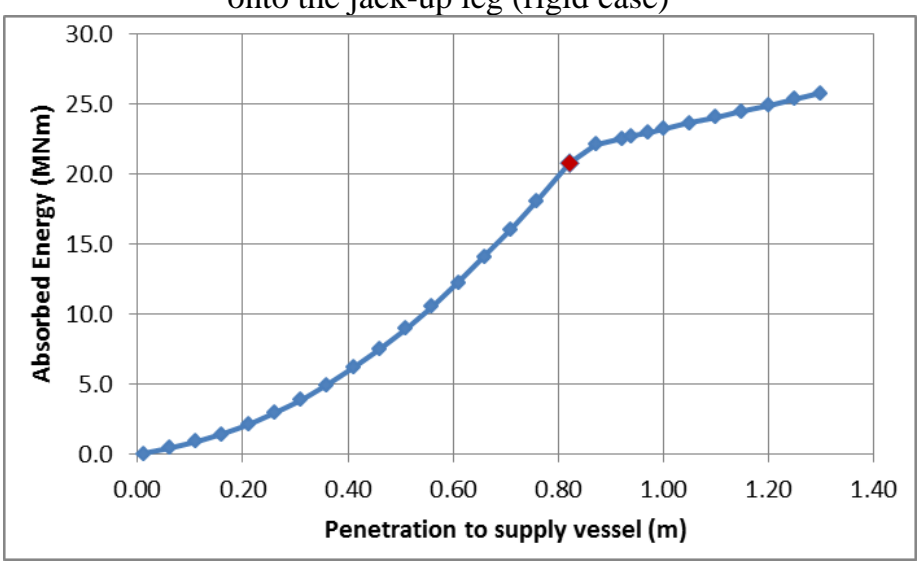

Figure 8. Energy-penetration curve of the supply vessel crushing onto the jack-up leg

\subsection{LOCAL DAMAGE TO JACK-UP LEGS}

The methodology used in the following to determine the local capacity of the jack-up legs against ship impact loads is a simplified approach based on stepwise determination of plastic hinges.

Fig. 9 shows a part of the leg of the considered jack-up rig for collision analysis. For a complete analysis this portion of the leg has to be analyzed for the five indicated load cases A to E.

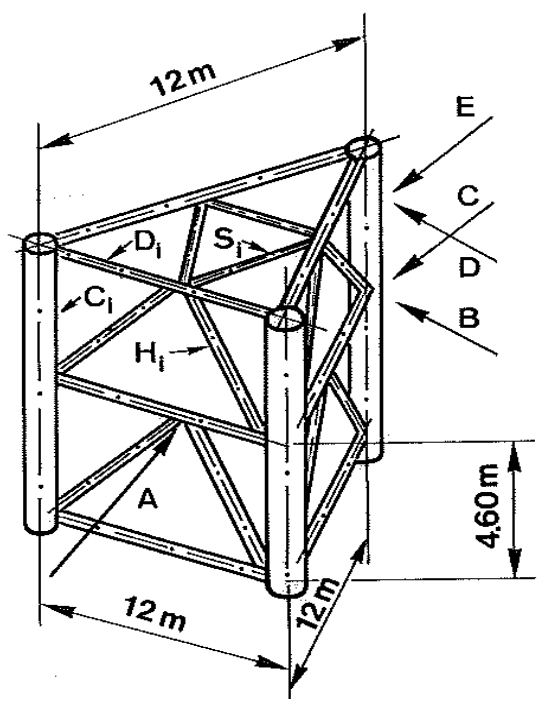

Figure 9. Part of jack-up leg with five load cases.

\subsubsection{Load case A: Bow collisions.}

Let us as a first example consider load case A which is a bow collision on a horizontal bracing member, see Fig. 10. Firstly, we assume that the bow of the colliding vessel is infinitely stiff and the impact is against the mid-part with the largest contact area and therefore, the largest bow collision force.

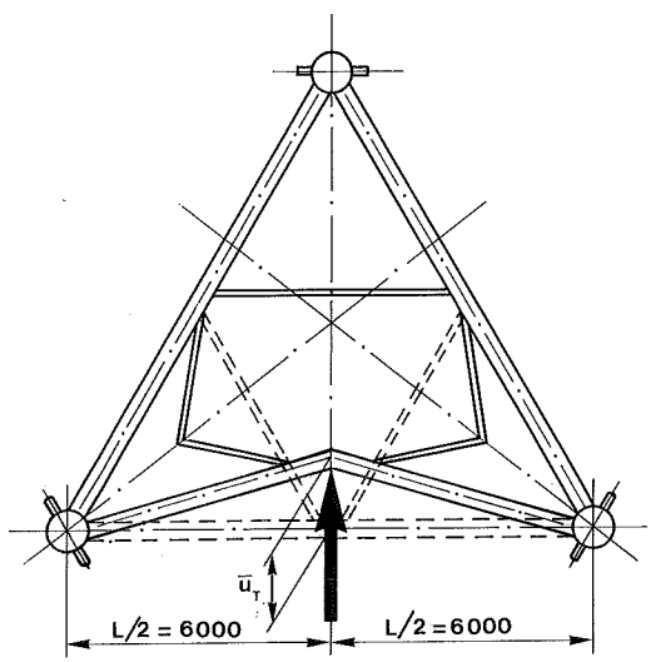

Figure 10. Central load on bracing (Load case A)

If we make the conservative assumption that the secondary bracing does not exist and that also the diagonal bracings are ineffective then we can determine the lower bound for the energy absorbed in the horizontal by membrane yielding simply as:

$E_{D}=\sigma_{y} A \Delta L$ 
where $\Delta \mathrm{L}$ is the plastic elongation of the bracing:

$\Delta L=L-\left(L^{2}-4 u_{T}^{2}\right)^{1 / 2}$

where $\mathrm{u}_{\mathrm{T}}$ is the plastic lateral displacement, i.e. total displacement minus elastic displacement. It should be noted that the bending phase of the deformation is neglected. The lateral collision forces may be written as:

$P_{c}=2 \sigma_{y} A \sin u_{T}$

or

$P_{c} \approx 2 \sigma_{y} A \frac{u_{T}}{L / 2}$

Of course, there is a practical limit to the elongation of a bracing before fracture occurs. If we take this limit to be $5 \%$, the yield stress of the bracing material to be $500 \mathrm{MN} / \mathrm{m}^{2}$, the cross sectional area of the bracing to be $0.0255 \mathrm{~m}^{2}$ and the bracing length $L=12 \mathrm{~m}$ then the maximum energy absorption limit in load case A is

$\mathrm{E}_{\mathrm{D}}=7.65 \mathrm{MJ}$

For load case A, only $5.88 \mathrm{MJ}$ is available for crushing for a 5 000 tons supply vessel and $10.25 \mathrm{MJ}$ is available for crushing for a 10,000 tons supply vessel. Therefore, the bracing has sufficient energy absorption capacity for the 5000 tons supply vessel in spite of the fact that we conservatively have assumed that the bow is infinitely stiff.

With the large tension forces in the horizontal bracing the adjacent chords are subjected to localized forces equal to the yield stress multiplied by the cross sectional area of the bracings, .i.e. $\mathrm{P}=12.8 \mathrm{MN}$, see Fig. 11. The effect of this load on the chords can be analyzed by neglecting all other bracings and applying the load at midpoint of the clamped - clamped chord of double bay length using a simple three hinge structural model. The chord cross section is shown in Fig. 12. With the actual scantlings of the chord it is found that this load can be accommodated without collapse.

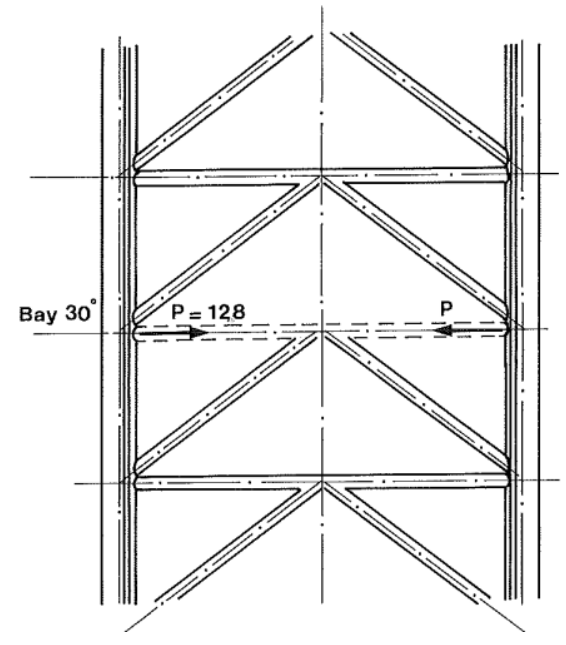

Figure 11. Transverse loading on cords in load case A.

\subsubsection{Load cases $B$ to E: Ship drifting to chords}

In order to investigate whether the strength of the chords is sufficient to resist the collision forces arising from the four load cases B to E, we shall study the strength of the chord modelled as a clamped - clamped beam column with a length equal to two bays, i.e. $\mathrm{L}=9.2 \mathrm{~m}$. Thus, we shall be conservative and neglect all the bracings at the mid bay. Furthermore we shall introduce the conservative assumption that the chord cross-section shown in Fig. 12 only consists of the tubular part.

From the analysis of the force - penetration of the midship section of the 5,000 tons supply vessel, we know that when the ship drifts sideways into the chord the maximum force will be:

$\mathrm{P}_{\max }=44.9 \mathrm{MN}$

This force may cause a localized deformation of the circular member. The energy which can be absorbed by localized deformation of the chord is expected to be small. Therefore we shall show, in the following example, that in this case the force exerted to the drifting ship hull is so large that the major energy absorption will take place in the ship side.

In Amdahl et al (2012) an expression for the force R which results in flattening of a circular tube with diameter $\mathrm{D}$ and wall thickness $\mathrm{t}$ is given as:

$R=\sigma_{y} \frac{t^{2}}{4} \sqrt{\frac{D}{t}}\left(22+1.2 \frac{H}{D}\right)\left(\frac{w_{d}}{D}\right)^{\frac{1.925}{3.5+\frac{H}{D}}}\left(\frac{4}{3}\left(1-\frac{1}{4}\left(1-\frac{N}{N_{p}}\right)^{3}\right)^{1 / 2}\right.$

where $\mathrm{w}_{\mathrm{d}}$ is the indentation and $\mathrm{H}$ is the contact height. The last term in the expression takes into account the effect of the axial force $\mathrm{N}$ in the tubular member. The expression given above is in accordance with the load flattening curves given in NORSOK 2004. 


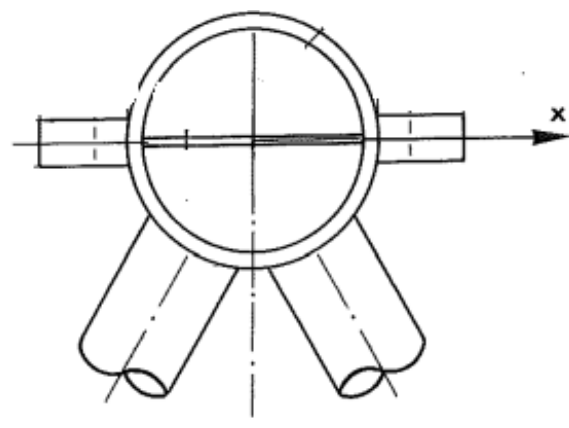

Figure 12. Cross-section of chord.

In the present case the stresses due to axial loads on the chord are small compared to the yield stress and the buckling stress $\mathrm{N}_{\mathrm{p}}$ and it is ignored in the following example.

If the chord depicted in Fig. 12 is approximated by the tubular part only and the chord material has a yield stress of 700 $\mathrm{MN} / \mathrm{m}^{2}$, a chord diameter of $1 \mathrm{~m}$ and an thickness $\mathrm{t}=0.053 \mathrm{~m}$ then we obtain the maximum indentation:

$\mathrm{W}_{\mathrm{d} 1}=0.134 \mathrm{~m}$

Figure 13 presented the force-penetration curves for both the supply vessel and the chord and Figure 14 presented the absorbed energy-penetration curves for both the supply vessel and the chord.

The results from these figures show that at the maximum crushing force of $\mathrm{P}_{\max }=44.9 \mathrm{MN}$, the energy absorbed by the supply vessel is $20.8 \mathrm{MJ}$; and the energy absorbed by the chord of the jack-up rig is $4.67 \mathrm{MJ}$ and the total crushing energy is 25.47MJ.

This is under the assumption that there is enough collision energy and the result rupture of the side shell of the supply vessel. However, the collision energy for crushing of the supply vessel and the jack-up structures is limited as presented in the Section 3.1 .

As shown in Section 3.1, the available collision energy for crushing is $5.03 \mathrm{MJ}$. Therefore, the actual damages to the side of the 5,000 tons supply vessel and to the chord of the jack-up rig will be much smaller. From Figures 13 and 14, we obtain that the energy absorbed by the supply vessel is $4.95 \mathrm{MJ}$ and the energy absorbed by the chord is only $0.08 \mathrm{MJ}$. The indentation to the chord is:

$\mathrm{W}_{\mathrm{d} 2}=5(\mathrm{~mm})$

A dent of this magnitude is estimated to reduce the plastic moment $\mathrm{M}_{\mathrm{p}}$ of the chord only by an insignificant amount according to NORSOK, 2004. That is, such an indentation will not jeopardize the safety of the jack-up in a one year storm.

All results of this example on collision energies, collision forces and penetrations can be summarized as in Figure 15 for easy reading.

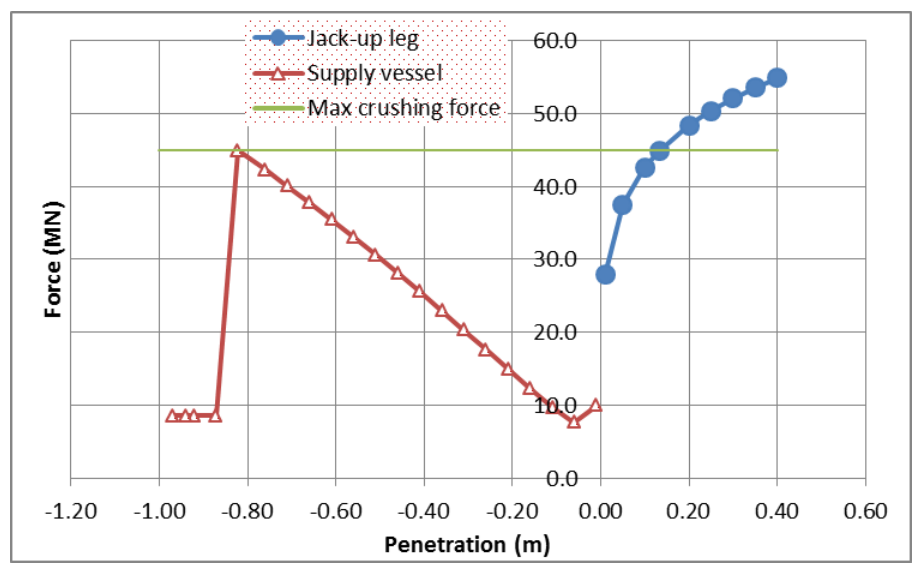

Figure 13. Force-penetration curves for sideway crushing of supply vessel and the chord of jack-up leg (note: penetrations of supply vessel were shown in negative values for the graphic purpose).

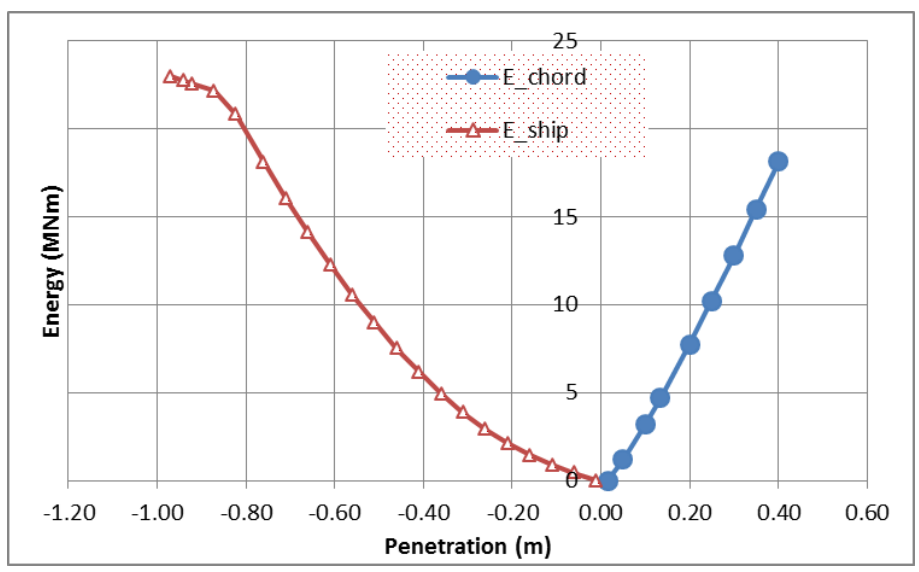

Figure 14. Energy-penetration curves for sideway crushing of supply vessel and the chord of a jack-up leg. 


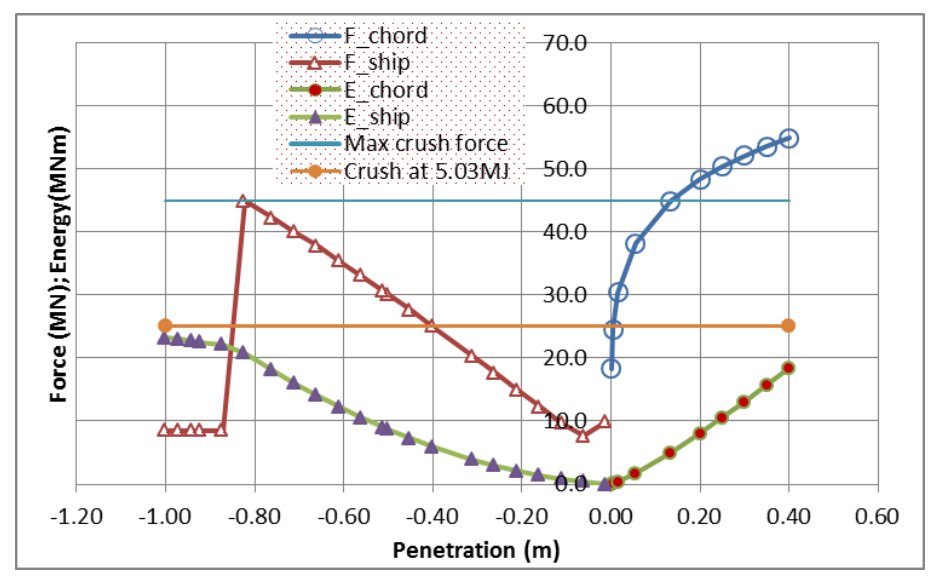

Figure 15. Force-penetration and energy-penetration curves for crushing of supply vessel and the chord of a jack-up leg.

\subsubsection{Overall jack-up strength and stability.}

As a final check of the ability of the rig to sustain the collision loads, the overall strength of the transversely impacted leg must be checked as well as the overturning moment must be ensured to be acceptable. Simplified expressions for the overturning moment in the worst case of central impacts can be found in Pedersen and Jensen (1991).

\section{CONCLUSION REMARKS}

The aim of this study has been to illustrate a simplified procedure for analysis of the ability of jack-up rigs to sustain operational and accidental impact loads from supply vessels serving these offshore structures.

An accurate assessment of damages to offshore installations caused by ship impact loads is complicated by the large amount of scenarios to be studied. These include various ship sizes and structures, impact locations, impact velocities and angles, etc. Therefore, even if comprehensive, time consuming, numerical analysis procedures exist, see Storheim \& Amdahl 2014, then simplified procedures are needed which are easy to apply and has sufficient accuracy to ensure the ability of the installation to resist the impact loads associated with normal operating conditions and accidental conditions such as supply vessels drifting out of control against the installation.

The focus of the paper has been on the capability of a large jack-up rig to sustain the accidental impacts from a longitudinally stiffened, ice-strengthened 5,000 tons supply vessel. It is shown that due to the flexibility of the jack-up rig only part of the initially available kinetic energy is released for crushing and that the collision energy is accommodated either by crushing of bracings in the jack-up legs in the case of bow impacts or by crushing of the side shell in case of sideway drifting into a leg without total collapse of the jack-up rig.

\section{ACKNOWLEDGMENTS}

The authors wish to thank Dr Sai Wong and colleagues at Lloyd's Register for their comments and support. The views expressed in this paper are those of the authors and are not necessarily those of Lloyd's Register. The main work of the paper was carried out during the time that the authors worked at the Technical University of Denmark.

Lloyd's Register and variants of it are trading names of Lloyd's Register Group Limited, its subsidiaries and affiliates. Lloyd's Register EMEA (Reg. no. 29592R) is an Industrial and Provident Society registered in England and Wales. Registered office: 71 Fenchurch Street, London, EC3M 4BS, UK. A member of the Lloyd's Register group.

Lloyd's Register Group Limited, its affiliates and subsidiaries and their respective officers, employees or agents are, individually and collectively, referred to in this clause as the 'Lloyd's Register'. Lloyd's Register assumes no responsibility and shall not be liable to any person for any loss, damage or expense caused by reliance on the information or advice in this document or howsoever provided, unless that person has signed a contract with the relevant Lloyd's Register entity for the provision of this information or advice and in that case any responsibility or liability is exclusively on the terms and conditions set out in that contract

\section{REFERENCES}

Amdahl, J.; Watam, R.; Hu, Z. \& Holmås,T., 2012, Broad side ship collision with jacket legs: Examination of NORSOK N-004 Analysis Procedure. OMAE Proceedings, Rio de Janeiro, OMAE2012-84266.

Gjerde, P.; Parsons,S.J. \& Igbenabor, S.C. 1999.: Assessment of jack-up boat impact analysis methodology, Marine Structures, 12,pp 371-401.

Lloyd's Register, 2014.: Guidance Notes for Collision Analysis. Published by Lloyd's Register Group Limited.

NORSOK Standard N-004, 2004: Design of steel structures, Appendix A, Design against accidental actions.

Paik, J.K. and Thayamballi, A.K., 2007, Ship-shaped Offshore Installations: Design, Building, and Operation, Cambridge University Press, Cambridge, UK.

Paik, J.K., 2007, Practical techniques for finite element modelling to simulate structural crashworthiness in ship collisions and grounding (Part I. Theory), Ships and Offshore Structures, Vol. 2, Issue 1, pp. 69-80.

Paik, J.K., 2007, Practical techniques for finite element modelling to simulate structural crashworthiness in ship 
collisions and grounding (Part II Verification), Ships and Offshore Structures, Vol. 2, Issue 1, pp. 81-85.

Pedersen, P.T., 2014, Risk assessment for ship collisions against offshore structures, Invited Lecture, Maritime Technology and Engineering- eds. Guedes Soares\& Santos, Taylor \& Francis Group, London, ISBN 978-1-138-02727-5.

Pedersen P. T. and Jensen J. J., 1991, Ship Impact Analysis for Bottom Supported Offshore Structures, Advances in Marine Structures II, Elsevier Applied Sciences.

Pedersen P. Terndrup \& Zhang S., 1998, On Impact Mechanics in Ship Collisions, Journal of Marine Structures, Vol. 11, pp. $429-449$.

Pedersen P. Terndrup \& Zhang S., 2000, Absorbed Energy in Ship collisions and Grounding - Revising Minorsky's Empirical Method", Journal of Ship Research, Vol. 44, No. 2, pp. $140-154$.

Samuelides, M., 2014, Recent Advances and future trends in structural crashworthiness of ship structures, Proceedings of $7^{\text {th }}$ International Conference on Thin-Walled Structures, Editors Paik; Kim and Song, ICTWS2014-0007. To be published in Ships and Offshore Structures?

Storheim M. and Amdahl J., 2014: Design of offshore structures against accidental ship collisions. Vol. 37, Marine Structures.

Yamada, Y. and Pedersen, P.T., 2008, A Benchmark Study of Procedures for Analysis of Axial Crushing of Bulbous Bows, Marine Structures, Vol. 21. Issues 2-3, pp. 257 293.

Zhang S., 1999, The Mechanics of Ship Collisions, PhD theses, Technical University of Denmark, Denmark, ISBN 8789502-05-1. 
